\title{
Metatarsal Bone Digit 4
}

National Cancer Institute

\section{Source}

National Cancer Institute. Metatarsal Bone Digit 4. NCI Thesaurus. Code C52788.

The fourth of the five long bones located in the mid-foot, which articulates proximally with the cuboid and lateral cuneiform bones at the tarsometatarsal joint and distally with the metatarsophalangeal joint. 